\title{
Una mirada geohistórica a la comunidad de Chiquiao, Estado Trujillo desde la etnografía
}

\author{
Geohistorical look at the community of Chiquiao, State Trujillo from the \\ ethnography
}

Jesús Alirio Briceño Briceño.

jesusbb20@hotmail.com

Universidad Nacional Experimental Francisco de Miranda

Recibido: $27 / 08 / 2017$

Aprobado: 25/09/2017

\begin{abstract}
RESUMEN
La realización de investigaciones en comunidades es de importancia ya que permite conocer sus características para el resguardo y divulgación de información hacia otras generaciones. Este trabajo tiene como propósito indagar la Geohistoria de la comunidad de Chiquiao, estado Trujillo desde la etnografía. Se contó con once (11) personas de las cuales diez (10) viven en la comunidad y uno (01) vivió en su niñez y juventud. El paradigma asumido el interpretativo, enfoque cualitativo bajo el método etnográfico. La técnica de recolección de datos es la entrevista en profundidad y la observación participante utilizando como instrumento la guía de entrevista, cuaderno de notas y dispositivos mecánicos. El análisis de la información fue por medio del análisis de contenido y la triangulación. Como consideraciones finales se tiene que en la comunidad han acontecido diversos hechos históricos, así mismo se ha desarrollado económicamente por su ubicación geográfica estratégica (fuentes hídricas, terrenos fértiles).
\end{abstract}

Palabras clave: Compendio Histórico, Caracterización Geográfica, Oralidad.

\begin{abstract}
The carrying out of investigations in communities is of importance since it allows to know its characteristics for the protection and dissemination of information towards other generations. This work aims to investigate the Geohistoria of the community of Chiquiao, Trujillo state from the ethnography. There were eleven (11) people of whom ten (10) lived in the community and one (01) lived in their childhood and youth. The
\end{abstract}




\section{CIENCIAMATRIA \\ Revista Interdisciplinaria de Humanidades, Educación, Ciencia y Tecnología \\ Año V. Vol. V. №9. Julio - Diciembre 2019 \\ Hecho el depósito de ley: pp201602FA4721 \\ ISSN-L: 2542-3029; ISSN: 2610-802X \\ Universidad Nacional Experimental Francisco de Miranda (UNEFM). Santa Ana de Coro. Venezuela}

Jesús Alirio Briceño Briceño

paradigm assumed the interpretative, qualitative approach under the ethnographic method. The technique of data collection is the in-depth interview and participant observation using as an instrument the interview guide, notebook and mechanical devices. The analysis of the information was through content analysis and triangulation. As final considerations one has to that in the community there have been several historical events, it has also been economically developed because of its strategic geographical location (water sources, fertile land)

Keywords: Historical Compendium, Geographical Characterization, Orality.

\section{INTRODUCCIÓN}

El conocimiento sobre identidad se establecen como complemento en la formación del ser humano, pues constituyen rasgos propios de países, estados, comunidades e individuos y va a reconocer siempre ese arraigo esencial que se debe poseer para construir ideales libres en base a lo que pertenece al ciudadano, generándose así un sentido de pertenencia. Así mismo, (Quevedo Pérez, Noriero Escalante, Cervantes Herrera, \& Zepeda del Valle, 2016, p. 45), señalan que "Las representaciones sociales como referente teórico conceptual, se convierten en una herramienta que nos permite identificar, conocer y valorar la forma de interactuar de determinado grupo social".

Desde lo planteado, integrando el significado de las vivencias y los saberes comunitarios se evidencia la necesidad de realizar una investigación que busque un abordaje de la visión geohistorica, con la finalidad de rescatar cada uno de los aspectos que en ésta se encuentran para así no perder esos conocimientos que los integrantes de las comunidades poseen.

Por tal razón, este trabajo tiene como propósito indagar la geohistoria de la comunidad de Chiquiao, estado Trujillo desde la perspectiva de sus pobladores y de esta manera, interpretar esos aspectos, teniendo como punto de partida la utilización del paradigma interpretativo, pudiéndose realizar un análisis enmarcado dentro del enfoque cualitativo a través del método etnográfico, en el cual se tome en consideración los aportes realizados por los habitantes de la comunidad. 


\section{CIENCIAMATRIA \\ Revista Interdisciplinaria de Humanidades, Educación, Ciencia y Tecnología \\ Año V. Vol. V. №9. Julio - Diciembre 2019 \\ Hecho el depósito de ley: pp201602FA4721 \\ ISSN-L: 2542-3029; ISSN: 2610-802X \\ Universidad Nacional Experimental Francisco de Miranda (UNEFM). Santa Ana de Coro. Venezuela}

Jesús Alirio Briceño Briceño

\section{TÓPICO CENTRAL DE LA INVESTIGACIÓN}

El desarrollo de la ciencia está permitiendo ofrecer una innovación en las diversas áreas de la vida, para obtener de ello una utilidad aplicada a la cotidianidad dando paso a una interacción continúa entre personas de un lugar a otro y a su vez obtener beneficios no solo para el progreso propio sino para contribuir en el avance continuo de la sociedad.

Por tanto, actualmente se están realizando indagaciones de los grupos humanos, con el fin de conocer cada una de las circunstancias que prescriben los valores internos y permite ir de manera gradual resguardando las identidades sociales, para evitar la pérdida de los elementos propios de las comunidades, y a su vez realizar un intercambio de estas.

De esta manera, resulta de gran beneficio las herramientas que brinda la evolución de la ciencia y en este caso la Geohistoria, para rescatar factores importantes de los orígenes de las comunidades y así mejorar las condiciones de identidad local que incide directamente en la sociedad en cuanto a la adquisición de conocimientos propios, por ello se hace necesario que las personas conozcan las culturas para permitir el desarrollo colectivo a través de las formas de interacción social e investigativas.

Actualmente, en Venezuela el Gobierno Nacional a través de los Ministerios aplican lineamientos de la Constitución de la República Bolivariana de Venezuela, donde establece la participación protagónica de la población para la construcción de una nueva sociedad, una transformación social a través de valores sociales y de identidad, en la cual se desarrolla e implementa de manera sistemática una serie de instrumentos en el ámbito de la educación. Asamblea Nacional Constituyente (1999:3)

Con ello, se ofrece un universo que permite innovar las diversas formas de vida para diversificar la investigación local, el estudio y el intercambio de conocimientos para favorecer con ello el aprendizaje activo, en este caso la historia y la geografía de una región determinada como alternativas para ampliar el proceso formativo de la población 


\section{CIENCIAMATRIA \\ Revista Interdisciplinaria de Humanidades, Educación, Ciencia y Tecnología \\ Año V. Vol. V. No9. Julio - Diciembre 2019 \\ Hecho el depósito de ley: pp201602FA4721 \\ ISSN-L: 2542-3029; ISSN: 2610-802X \\ Universidad Nacional Experimental Francisco de Miranda (UNEFM). Santa Ana de Coro. Venezuela}

Jesús Alirio Briceño Briceño

que se encuentra tanto en la educación formal como informal y hacerlos entes activos en la sociedad.

Es necesario hacer referencia que esta investigación se enfocó en indagar la Geohistoria de la comunidad de Chiquiao, estado Trujillo desde la etnografía. Esta comunidad es un centro poblado que está ubicado en el límite del estado Trujillo con el estado Mérida y posee características que la hacen única desde el punto de vista histórico y geográfico. Para ello, se realizó una caracterización con el fin de encontrar todas aquellas particularidades e informaciones que en esta comunidad se encuentran y de esta manera construir un compendio teórico necesario para dar la relevancia que merece por su protagonismo en la Venezuela que hoy se posee.

Esto se ejecuta con la finalidad de hacer resaltar la cultura, historia y sobre todo las vivencias físico, sociales y ambientales que han ocurrido en ese espacio geográfico y que solo los propios habitantes de la comunidad conocen y que se debe agrupar para que sean impartidos a los futuros profesionales que van a dar vida educativa en este país, además pueden ser implementadas a través de unidades curriculares relacionadas a la geografía e historia de pequeñas localidades.

\section{REFERENTES TEÓRICOS}

\section{La Geohistoria}

La geohistoria surge como una necesidad e inquietud para evidenciar teorías relacionadas con el desenvolvimiento del hombre dentro del campo social y relacionarlas con el contexto físico en el cual este se desenvuelve y que determinan las características sociales. De esta manera, construir una geohistoria significa:

Ubicar los problemas humanos tales que sean colocados en el espacio, en lo posible cartografiados, una geografía humana inteligente...que los ubique en el espacio teniendo en cuenta el tiempo: desatar la geografía de esta búsqueda de realidades actuales a las que ella se aplica exclusivamente, para repensar, 


\section{CIENCIAMATRIA \\ Revista Interdisciplinaria de Humanidades, Educación, Ciencia y Tecnología \\ Año V. Vol. V. №9. Julio - Diciembre 2019 \\ Hecho el depósito de ley: pp201602FA4721 \\ ISSN-L: 2542-3029; ISSN: 2610-802X \\ Universidad Nacional Experimental Francisco de Miranda (UNEFM). Santa Ana de Coro. Venezuela}

Jesús Alirio Briceño Briceño

con sus métodos, las realidades pasadas. Braudel (1982) citado en Avella (2002: 13)

Por tal razón, el Enfoque Geohistórico "es una propuesta teórico-metodológica para el análisis del espacio geográfico desde una perspectiva interdisciplinaria, entendiendo al espacio como producto social, síntesis de la acción de los grupos humanos consecuencia de una realidad histórica" Tovar (1986) citado en Aponte (2006:3).

De la misma manera, se conceptualiza como la "relación entre la geografía y la historia; una modalidad de interdisciplinariedad obligante en el estudio del espacio y su dinámica. Lo geográfico forma parte del proceso histórico y necesita de la historia para ser explicado socialmente" Santaella (1990) citado en Aponte (2006:3).

Por tal razón, se describe en lo temporal y lo espacial se apoyan en la categoría proceso, el espacio (nacional, urbano, rural, fronterizo, industrial, comercial...) presenta una dinámica, complejidad, heterogeneidad y especificidad que lo define, de acuerdo a las condiciones históricas determinadas. Para el análisis del espacio se parte del presente, como síntesis del proceso.

Así mismo, Ceballos (2003:1) menciona "que la Geohistoria se erige en una nueva disciplina científica que responde al "sintético complejo de la realidad" o sistema de equilibrio Sociedad /Naturaleza. Se manifiesta desde el espacio, (preocupación de la geografía) y desde el tiempo (preocupación de la historia)".

Afirma Tovar citado en Santaella (2005:9). "queda establecido que la Historia es la Geografía en el tiempo, mientras que la Geografía es la Historia en el espacio". Es decir, que estas dos ciencias van a permitir estudiar al ser humano cada una desde su punto de vista de su estructuración científica y deben estar en constante vinculo para que de esta forma se constituya una generación de factores teóricos que van a explicar la dinámica actual, haciendo énfasis a que la geografía estudia en espacio natural, donde convive el hombre y para que esto se complemente de manera amplia se debe 


\section{CIENCIAMATRIA \\ Revista Interdisciplinaria de Humanidades, Educación, Ciencia y Tecnología \\ Año V. Vol. V. №9. Julio - Diciembre 2019 \\ Hecho el depósito de ley: pp201602FA4721 \\ ISSN-L: 2542-3029; ISSN: 2610-802X \\ Universidad Nacional Experimental Francisco de Miranda (UNEFM). Santa Ana de Coro. Venezuela}

Jesús Alirio Briceño Briceño

indagar las características culturales e históricas que se encuentran en ese entorno de convivencia social.

\section{METODOLOGÍA UTILIZADA}

Para la realización de la investigación se utilizó el paradigma interpretativo, bajo el enfoque cualitativo y método etnográfico, en donde se realizó un abordaje utilizando herramientas acordes a este paradigma. Los sujetos estudiados corresponden a un grupo de personas que forman parte de la realidad a estudiar, pues a lo largo de la vida ha tenido experiencias y a medida que se va realizando el intercambio permitió conocer algunos elementos, que son narrados a través del relato cotidiano durante la interacción entre éstos con el investigador.

La investigación fue realizada en la comunidad de Chiquiao, ubicada en la parroquia Mesa de Esnujaque, Municipio Urdaneta, estado Trujillo, al sur-oeste de la ciudad capital Trujillo, a una altura entre 1650 y 1700 m.s.n.m aproximadamente, ejecutando las entrevistas en las viviendas de cada uno de los informantes.

Por ello, participaron once (11) informantes quienes han vivido parte de su vida en la comunidad de Chiquiao, se escogieron porque poseen conocimientos confirmados en geo-historia del mencionado lugar y estuvieron motivados para la realización de la investigación. La recolección de información se llevó a cabo a través de la entrevista en profundidad y la observación participante, utilizando como instrumento la guía de entrevista, cuaderno de notas y dispositivos mecánicos para guardar sonidos e imágenes.

El análisis de la información se dio por medio del análisis de contenido, se realizó extrayéndose de las entrevistas de los informantes que se encontraban grabadas y se transcribió de forma digital organizándose de acuerdo a cada uno de los propósitos, luego de ello se utilizó la validación de la investigación por medio de la triangulación a través de entrevistas, referentes teóricos y aportes del investigador. 


\section{CIENCIAMATRIA \\ Revista Interdisciplinaria de Humanidades, Educación, Ciencia y Tecnología \\ Año V. Vol. V. №9. Julio - Diciembre 2019 \\ Hecho el depósito de ley: pp201602FA4721 \\ ISSN-L: 2542-3029; ISSN: 2610-802X \\ Universidad Nacional Experimental Francisco de Miranda (UNEFM). Santa Ana de Coro. Venezuela}

Jesús Alirio Briceño Briceño

\section{ANÁLISIS DE LA INFORMACIÓN}

La historia de una comunidad se encuentra muchas veces guardada en libros de antiguas ediciones, en objetos naturales y artificiales pero también, en la memoria de quienes hoy, son el resultado de una comunicación intergeneracional surgida a través de los años; estos son, las personas mayores, quienes poseen una gran sabiduría, forman parte de la historia viva y son la fuente de información más valedera de la sociedad.

Por tanto, que para describir la geo-histórica de la comunidad de Chiquiao, se recurrió a estos procedimientos descritos en la metodología que han dado origen a lo que se representa a continuación.

De los primeros hechos que acontecieron en la comunidad, poco se tiene registro; pero de acuerdo a diversas observaciones y la investigación de obras históricas de comunidades vecinas e historia regional, se ha encontrado que esta localidad surge como centro poblado a causa de los factores ambientales y geográficos, como lo son: mesetas, tierras fértiles y la fuente hidrológica "el rio Motatán" que fluye en las orillas; condiciones favorables para la sobrevivencia, asentamiento y desarrollo de nuestros antepasados indígenas.

En virtud de lo descrito anteriormente, mediante referencia oral menciona:

Antes de llegar los Españoles, durante la época de la conquista en esa zona poblaban los indios (indígenas); eran tres (3) familias o tres (3) tribus, ubicadas en la ribera del rio Motatán, estas eran; los Garabuya ubicados de lo que es actualmente la Joya hacia abajo, los Buyaqui pertenecían a lo que es hoy Chiquiao y Mucumis y los Buyayi ubicados para subir a La Mesa de Esnujaque. Villareal E. (2011).

Es de acotar, que estas pequeñas tribus distribuidas en un espacio geográfico pertenecían a la gran nación Timoto y Cuica cuyos territorios hoy son el estado Mérida 


\section{CIENCIAMATRIA \\ Revista Interdisciplinaria de Humanidades, Educación, Ciencia y Tecnología \\ Año V. Vol. V. No9. Julio - Diciembre 2019 \\ Hecho el depósito de ley: pp201602FA4721 \\ ISSN-L: 2542-3029; ISSN: 2610-802X \\ Universidad Nacional Experimental Francisco de Miranda (UNEFM). Santa Ana de Coro. Venezuela}

Jesús Alirio Briceño Briceño

y Trujillo, ubicándose el límite entre estas dos etnias, la línea geográfica que separa en la actualidad las jurisdicciones anteriormente nombradas.

Los Timotes, pues que así los llamaré, tenían por confinantes los pueblos siguientes: al norte, o sea sobre las orillas del Lago, los Bobures y Motilones; al sur sobre el arranque de los llanos, los Toboros, Caros y Coyones. Al Oeste los Mombures y Aviamas del Táchira, dependientes o confinantes de los Chitareros; y al Este la nación de Cuicas, que, compuesta de pueblos de distintos nombres, habitaban lo que es hoy Estado Trujillo. Los límites que tenían señalados entre sí, los Timotes y Cuicas, son precisamente los mismos que dividen hoy los estados Mérida y Trujillo. Lares (1950). Citado en Gordones, G; Meneses L. (2004).

Así mismo, durante esta época las sociedades indígenas Timoto y Cuica eran las más organizadas en el territorio nacional, pues desarrollaron la agricultura aprovechando las tierras fértiles a través de la realización de terrazas en los sitios inclinados, utilizando en ello la piedra para el desarrollo de esta infraestructura; en cuanto a su arquitectura realizaban muros de piedra para la identificar limites o linderos y sus casas las realizaban como bohíos utilizando materiales como paja, piedra y tierra esto con el fin de mejorar las condiciones de temperatura en la parte interna de la vivienda, características principales de estas civilizaciones.

Por otra parte, siguiendo con la investigación sobre las huellas autóctonas en este sector, se encuentra que de acuerdo a los registros o publicaciones de obras históricas, existe una similitud en los sonidos de las palabras de otros sectores cercanos con el de la palabra Chiquiao; según Jahn A (1927) quien menciona que la palabra "Chi se refiere a la preposición cuya definición es encima o sobre"; así mismo, haciendo referencia a la tradición oral Gómez G. (2011) expresa "Chi es un sonido proveniente del vocablo indígena Timoto y Cuica que significa agua". De la misma manera, Espinosa J (2011) indica:

Hay alguna referencia que hacen alusión a Chiquiao como uno de los Caciques de una etnia indígena de la zona de Trujillo, específicamente 


\section{CIENCIAMATRIA \\ Revista Interdisciplinaria de Humanidades, Educación, Ciencia y Tecnología \\ Año V. Vol. V. No9. Julio - Diciembre 2019 \\ Hecho el depósito de ley: pp201602FA4721 \\ ISSN-L: 2542-3029; ISSN: 2610-802X \\ Universidad Nacional Experimental Francisco de Miranda (UNEFM). Santa Ana de Coro. Venezuela}

Jesús Alirio Briceño Briceño

del municipio Urdaneta, pero precisado como tal no hay información, eso es solo referencias orales; gente que sostuvo, como por ejemplo el Abogado de La Mesa de Esnujaque Jesús Briceño; quien sostuvo, que hacía alusión a un Cacique de los grupos indígenas Timotes y Cuicas que habitaron lo que es hoy en día el municipio Urdaneta".

Sin embargo, las afirmaciones orales encontradas coinciden que existe una gran similitud en la raíz del significado de la palabra, pues se llega a la conclusión que "Chiquiao" deriva de un vocablo indígena y que, aunque no se tiene una definición exacta, con los datos orales, el estudio y análisis de este término con otros existentes, se concluye que el significado es una herencia lingüística y una huella tradicional de nuestros antepasados indígenas.

Por otra parte, los accidentes geográficos naturales existentes formados por el rio Motatán y por la actividad montañosa fueron aprovechados y utilizados por las civilizaciones autóctonas, y establecieron una red de comunicación a lo largo de ésta comunidad, conocidos también como los caminos de indios así lo menciona Kauman C (1989) citado en Pimiento G. y otros (2008) "tales obstáculos no debieron ser gran impedimento, porque ya existían caminos construidos por los indígenas", es decir, la comunidad geográficamente se encuentra ubicada en un lugar estratégico para la comunicación y el comercio con otros sectores.

En otro orden de ideas, la historia de esta comunidad también se ve reflejada durante época de la conquista cuando para el año de 1559 en su afán de obtener territorios más extensos, dos (2) conquistadores Juan de Maldonado y Francisco Ruiz decidieron llegar a un acuerdo, para lo cual designaron a Alonso Rodríguez de Mercado quien demarcó la zona quedando de la manera siguiente:

Comenzando en la desembocadura del Rio Pocó en el sur del Lago Coquivacoa, siguiendo aguas arriba hasta su nacimiento: de allí subieron al alto de los páramos Mukumbuh, Chugué, Barabulta; Altos del Boquerón, Alto de Cuica y bajaron hasta Chiquiao, pasaron por la parte opuesta del Motatán, siguiendo por MuKumis hasta el zanjón de 
Matos y de allí al Alto de Durí, para ir buscando el nacimiento del rio Chinó y finalizar en el curso del rio Santo Domingo. Villareal, E (2008).

Se puede mencionar otro acontecimiento que sucedió en la comunidad de Chiquiao, debido a que los grupos indígenas de América del Sur se organizaron para mitigar los fuertes combates y la imposición de leyes económicas (recaudación de impuestos) por la producción agrícola de los rubros tradicionales que nutrían el mercado comercial para ese tiempo como el cacao, tabaco, entre otros; estos impuestos defendían los derechos de los conquistadores y explotaban a los indígenas; por ello, a causa de lo mencionado comienza en Perú la insurrección del Rey Inca Túpac Amarú que tuvo comienzo el 04 de Noviembre de 1780 denominada la rebelión de Los Comuneros y en la cual se fue sumando otras poblaciones; es así, que el 7 de agosto partieron a Timotes una tropa de 1000 hombres y estando allí la orden fue dirigirse a la Raya límite entre Mérida y Trujillo:

El 16 de agosto la angustia cundió entre ambos bandos. Por su parte, los rebeldes deciden avanzar desde Timotes hacia La Raya, dispuestos a cumplir con su cometido. Los realista, al mando de Sancho Briceño y Vicente Cardona, estratégicamente colocados en La Mesa de Esnujaque y ya enterados de la proximidad de los auxilios militares de Maracaibo, resuelven impedir a toda costa que los insurgentes se adentraran en territorio trujillano. Muñoz (1971).

Es así, que el espacio geográfico de la comunidad de Chiquiao, ha tenido gran significado dentro de la historia de Venezuela, fue igualmente el territorio limítrofe de las ancestrales civilizaciones indígenas de nuestro país, los Timoto-Cuica; de la misma forma, los conquistadores establecieron sus territorios tomando en cuenta las demarcaciones de los estos indígenas, igualmente este límite fue para una época la línea divisional entre Venezuela y Nuevo Reino de Granada.

Después de estos hechos históricos, no se ha encontrado otra referencia bibliográfica que mencione a esta comunidad; sin embargo, es probable que a partir de esa fecha mencionada y por la posición estratégica del sector, vivió momentos de luchas entre los 


\section{CIENCIAMATRIA \\ Revista Interdisciplinaria de Humanidades, Educación, Ciencia y Tecnología \\ Año V. Vol. V. No9. Julio - Diciembre 2019 \\ Hecho el depósito de ley: pp201602FA4721 \\ ISSN-L: 2542-3029; ISSN: 2610-802X \\ Universidad Nacional Experimental Francisco de Miranda (UNEFM). Santa Ana de Coro. Venezuela}

Jesús Alirio Briceño Briceño

conquistadores y los indígenas integrantes de la cultura milenaria Timoto-Cuica, pues fue tomada en cuenta para ingresar y luego transitar por este territorio.

Estas luchas se ha de suponer que sucedió por impedir la invasión de ese grupo extranjero, pero sin embargo a pesar de los esfuerzos de estos grupos autóctonos; la gran civilización asentada en esta región fue poco a poco extinguiéndose a tal punto que tuvieron que emigrar a altas serranías para poder sobrevivir y evitar el sometimiento.

Por otra parte, con el pasar del tiempo, en lo que es hoy Chiquiao y sus comunidades vecinas los habitantes indígenas mermaron, desaparecieron o huyeron, por lo tanto, los conquistadores fueron habitando las zonas estratégicas; es por ello, se puede explicar las diversas casas antiguas coloniales que se encontraban en comunidades y en este el caso de la vivienda de Chiquiao ubicada a orillas del rio Motatán, donde se menciona que pernoctó Simón Bolívar, cuya estructura era de tapia y teja con una arquitectura característica de estos grupos foráneos. De esta manera lo expresa García M. (2011) en su relato "En la casa de Chiquiao, se hospedó Simón Bolívar, la gente decía, cuando cometieron el error de faratar esa casa, verdad, siendo tan útil como era esa, la casa era de corredor, tremendo corredor, una sala, (ríe) todo ha cambiado".

De la misma manera, lo menciona mediante la tradición oral:

Muchas historias de cuando Simón Bolívar que posó allá,... en el rancho aquel donde vive Ismael, la casa vieja pues, yo conocí esa sala donde posó Simón Bolívar, pero cuando yo la conocí eso era una sala muy grande, pero conocí el contorno así, las paredes de piedra ya se estaban cayendo iban a media paredes, entonces eran que me decían los viejitos de antes que era donde había posao Bolívar en esa sala que era muy grande, pero toda la vida ha sido Chiquiao. Díaz A. (2011).

Otro de los acontecimientos que han ocurrido, es la construcción de la acequia comunal que sin duda alguna es la fuente que ha dado vida a las tierras fértiles que en esta 


\section{CIENCIAMATRIA \\ Revista Interdisciplinaria de Humanidades, Educación, Ciencia y Tecnología \\ Año V. Vol. V. No9. Julio - Diciembre 2019 \\ Hecho el depósito de ley: pp201602FA4721 \\ ISSN-L: 2542-3029; ISSN: 2610-802X \\ Universidad Nacional Experimental Francisco de Miranda (UNEFM). Santa Ana de Coro. Venezuela}

Jesús Alirio Briceño Briceño

comunidad se encuentran; por lo tanto, para el año 1881 aproximadamente según cuenta la tradición oral:

No sé muy bien el origen de la cequia, pero según lo que me decía mi Papá, los que abrieron esa cequia fue Los Salcedo, Dámaso Salcedo, (su abuelo) y los hijos del; bueno esos iban, iban, supongo que iban abriendo una cequiecita, iban llevando el agua y por ahí se dirigían y abrían la sequía; supongo de acuerdo a las conversaciones de mi Papá Indalecio, que tiene como 130 años la cequia, como en el 1881 más o menos la hicieron, tiene como 130 años; eso era pa' riego y pa' tomar también, esa era del rio Motatán, era para regadío pero tomaba el agua uno también de esa, yo también tome mucha agua de esa. Briceño J. (2011).

Este sistema de riego era con la finalidad de aprovechar esos espacios agrícolas y mejorar la productividad de la zona, siguiendo los conocimientos indígenas transmitidos de generación en generación, y era para nuestros antepasados una técnica innovadora; así mismo, esta agua de la acequia matriz, era dispersada hacia las diferentes parcelas a través de surcos que se derivaban de la acequia principal.

Esta afluencia artificial de agua, está construida al oeste de la comunidad ubicada a pie de montaña y a lo largo de la misma, iniciando en cerca del límite Trujillo - Mérida y culminando en la Quebrada de las Avispas, las aguas recorren por tierra y por lo tanto, esto con el pasar de los años han generado un micro ecosistema a través de la formación de una flora y a su vez fauna a orillas de la misma y la impermeabilización natural en su trayecto a causa del paso constante del agua.

En otro orden de ideas, debido al crecimiento económico provocado por las políticas agrícolas implantadas por el gobierno de Antonio Guzmán Blanco y en vista de mejorar la accesibilidad para la comercialización de los rubros, menciona en un comunicado del Gobernador de la sección de Trujillo al Presidente del Grande Estado de los Andes que expresa:

El Gobierno de la Sección ha emprendido la apertura de un nuevo camino de Valera a Timotes por la cañada que sirve de lecho al 


\author{
CIENCIAMATRIA \\ Revista Interdisciplinaria de Humanidades, Educación, Ciencia y Tecnología \\ Año V. Vol. V. №9. Julio - Diciembre 2019 \\ Hecho el depósito de ley: pp201602FA4721 \\ ISSN-L: 2542-3029; ISSN: 2610-802X \\ Universidad Nacional Experimental Francisco de Miranda (UNEFM). Santa Ana de Coro. Venezuela
}

Jesús Alirio Briceño Briceño

Motatán, con el fin de ahorrar, poco más o menos trece kilómetros de distancia. El trabajo empezó el 04 de Julio últimos con las cuadrillas de Valera, Carvajal, Quebrada, Jajó y la Mesa de Esnujaque. Periódico "El Trujillano" del 13 de Agosto de 1881.

De esta forma, es cuando se comienza a efectuar los trámites para la construcción de vías de comunicación terrestre. En este sentido, de acuerdo a la información oral suministrada, indica:

La carretera pasaba por ahí, por donde..., por Villa Mercedes pa' arriba por la orilla del rio y salía por ahí en Chiquiao y de ahí cruzaba y salía allá a la frutería y cogía hacia allí por donde mi Papá Alecio que todavía se puede observar y después seguía hacia donde Los Ruices, subía por detrás donde la finada Lupe y salía a la Raya; esa era la que funcionó porque según lo que me contaron, hicieron otro trayecto que fue el primero pero no funcionó que subía por donde la señora Julia Araujo, subía por terrenos de Hermenegilda Salcedo y llego hasta terreno de Teo, ahí donde hay una mata de Chirimoya, en este trayecto actualmente existen muros y alcantarillas que hacen ver la existencia de este camino. Briceño E (2011).

Así mismo, siguiendo este lineamiento se encuentra anécdotas y recuerdos del gran trabajo realizado en la construcción de La Variante:

Para el año de 1945 aproximadamente comenzamos a trabajar para el Ministerio de Obras Públicas, éramos 60 hombres, hicimos aquí en La Raya un puente alto (muro)... ahí trabajamos 11 días... también había una maquina abriendo la carretera nueva y un patrón pa' dirigir la maquina; la maquina iba alante y nosotros atrás abriendo la carretera y después la alcantarilla, además también minábamos las peñas. Yo trabajé en los tramos Motatán- Valera, Valera-La Puerta-Timotes; y hasta ahí en Timotes donde baja el agua en la avenida, esa alcantarilla la montamos nosotros. Villareal I (2011).

Con lo anteriormente expuesto, se puede decir que la comunidad de Chiquiao tuvo tres (3) trayectos de carretera de los cuales el primero no funcionó porque no logró subir hasta la Raya por la dificultad de los accidentes en el relieve, el segundo que fue la conocida carretera nacional que cruzaba todos los terrenos de la comunidad y salía a la 


\section{CIENCIAMATRIA \\ Revista Interdisciplinaria de Humanidades, Educación, Ciencia y Tecnología \\ Año V. Vol. V. №9. Julio - Diciembre 2019 \\ Hecho el depósito de ley: pp201602FA4721 \\ ISSN-L: 2542-3029; ISSN: 2610-802X \\ Universidad Nacional Experimental Francisco de Miranda (UNEFM). Santa Ana de Coro. Venezuela}

Jesús Alirio Briceño Briceño

raya de los cuales aún permanecen algunos trayectos y actualmente algunos tramos son utilizados para el acceso a terrenos de propiedad privada y el último fue la que actualmente se tiene, su construcción pasa por la comunidad de Chiquiao se realizó aproximadamente en el año de 1945 conocida comúnmente para esos años como "La Variante" del tramo carretero Mendoza Fría-La Raya de Chiquiao, llamada así por ser la otra vía de comunicación terrestre alterna para acceder de Valera a Timotes; sin embargo esta obra fue desplazando desde el sector de Villa Mercedes hasta La Raya el camino nacional construido en los años de 1920.

Por otra parte, uno de los informantes expresa en su tradición oral, que existen caminos reales Salcedo H. (2011), "Los caminos reales que conozco es el de la cuesta de Las Higueras, que sube de aquí de Chiquiao hasta conduce hasta Las Mesas, el Hato todo eso era camino real, ese es el camino que yo conozco".

Es de gran relevancia, que este es un sitio de paso porque en este pequeño territorio pasaba el camino nacional que se bifurcaba en diferentes trayectos, para la Mesa de Esnujaque, la Lagunita o La Puerta a través del camino de la Mocotí y por medio del camino nacional hacia La Cuica - Las Mesas cuyo trayecto dirigía a la zona sur del Lago de Maracaibo. Debido a estas evidencias, se puede indicar que estos caminos llevan marcados los pasos de muchas tropas, héroes, arreos de mulas y campesinos que viajaban para los combates que acontecían en otras jurisdicciones y también para el intercambio comercial.

Otro hecho pertinente a mencionar es, que existió un puesto de control ubicado en la comunidad con el propósito de establecer la vigilancia epidemiológica al pasar, así lo indica García J (2011) durante la entrevista que "Hubo una alcabala, ahí donde el finao Ramón, de la Guardia, había una enfermedad pues y lo hacían pasar por una batea, así (hizo la forma de la batea con las manos) y le echaban un desinfectante, cuando pasaba uno se mojaba los pies y salía, hay no se quedaba nadie sin pasar, ajuro 


\section{CIENCIAMATRIA \\ Revista Interdisciplinaria de Humanidades, Educación, Ciencia y Tecnología \\ Año V. Vol. V. №9. Julio - Diciembre 2019 \\ Hecho el depósito de ley: pp201602FA4721 \\ ISSN-L: 2542-3029; ISSN: 2610-802X \\ Universidad Nacional Experimental Francisco de Miranda (UNEFM). Santa Ana de Coro. Venezuela}

Jesús Alirio Briceño Briceño

(obligado) todos". En otro orden de ideas, tomando en consideración elementos geográficos se encuentra que:

La comunidad de Chiquiao, se encuentra ubicada en el Municipio Urdaneta, estado Trujillo, al sur-oeste de la ciudad capital Trujillo, a una altura entre 1650 y 1700 m.s.n.m aproximadamente. Sus límites son: Al norte con la comunidad de Villa Mercedes, al sur con el sector El Puente (Vega de Timotes o La Raya), al este con la comunidad de Mucumis, al oeste con el Alto de la Cuica y la Cuica. Desde otra óptica, la mayoría de los habitantes practican la religión católica y las festividades que celebran son la de San Benito de Palermo (patrono), con los giros, quienes bailan en su honor, celebrándose el segundo domingo de febrero, así mismo, la festividad anual de San Pancracio los días 12 de mayo.

Igualmente, su relieve está constituido fundamentalmente por pequeñas laderas y planicies ubicadas al pie de montaña, los terrenos por lo general son ubérrimos, ricos en minerales y materia orgánica lo que permite que sean explotados en casi su totalidad, para la producción agrícola. También se encuentran grandes rocas y piedras, que de acuerdo a su estructura se puede determinar que son de rio; existen en algunos lugares rocas porosas que indican la probable existencia de antiguas nacientes de aguas. El río que atraviesa la comunidad es el Motatán, nace en el páramo del Collado del Cóndor conocido generalmente como el Águila, estado Mérida, y pasa de Sur a Norte a orillas de la comunidad, siendo este el límite con la comunidad de Mucumis. La temperatura media, oscila entre 17 a $25^{\circ} \mathrm{C}$, durante el año existen dos periodos de tiempo; de lluvia, entre Abril-Mayo y Septiembre-Octubre y parte de Noviembre con pocas lluvias por ser zona árida de paramo, y el de sequía a partir de mediados de Noviembre- Diciembre-Enero-Febrero y parte de Marzo. De la misma forma, para los meses de Junio-Julio-Agosto por lo general son meses de sequía, acompañado con lloviznas y fuertes vientos provenientes de las altas montañas de Mérida, este fenómeno conocido por el lenguaje coloquial de los pobladores como "Parameando". 


\section{CIENCIAMATRIA \\ Revista Interdisciplinaria de Humanidades, Educación, Ciencia y Tecnología \\ Año V. Vol. V. №9. Julio - Diciembre 2019 \\ Hecho el depósito de ley: pp201602FA4721 \\ ISSN-L: 2542-3029; ISSN: 2610-802X \\ Universidad Nacional Experimental Francisco de Miranda (UNEFM). Santa Ana de Coro. Venezuela}

Jesús Alirio Briceño Briceño

La flora que está presente en la comunidad de Chiquiao, se caracteriza por poseer escasa vegetación, constituida principalmente por cactus, cují, eucaliptos y sen sen en los cerros localizados en la parte oeste de la comunidad, así mismo, al pie de estos pasa la acequia comunal y a lo largo de ella se ha formado un micro-ecosistema con el paso de los años, mientras que en la zona Este cerca del rio Motatán se encuentra una pequeña porción de abundante y variada vegetación, entre los árboles frondosos que predominan se encuentran los uvitos, guacharacos, jovicoes, lecheros y tártagos, también se observan árboles frutales como el jumangue, guayaba de monte, chirimoya, higos, café y naranja.

En cuanto a la fauna, se encuentran aves como los azulejos, el garrapatero, el gavilán, las pirulatas, cucaracheros y los gallitos; el faro o rabipelado, las lagartijas, los matos de agua, serpientes (corales, mapanares, tigras, cascabeles, sabaneras), las mariposas de San Juan que bajan de las altas montañas del páramo, los insectos de color ladrillo llamadas típicamente vaquitas.

En otro sentido, Abreu C (2012) en su tradición oral expresa que en cuanto a la agricultura "Se sembraba maíz, arveja, garbanzo, trigo no porque era muy caliente, eso era pa' vender, frutas, que iban a estar sembrando frutas, no, la Chirimoya, había una Chirimoya que era más rica, que rica en mi casa; atrás, pero mira eso era así... grandes las Chirimoyas y he tenido unos deseos".

Por tanto, la economía local se caracterizaba por el cultivo de caraota, arveja, maíz, garbanzo y trigo, cría de ganado y aves a nivel doméstico para la subsistencia y trueque; la producción de caña de azúcar en las planicies de la comunidad para ser comercializada en los trapiches cercanos (Mucumis y Villa Mercedes); sin embargo, para el año de 1955 aproximadamente hubo un desplazamiento de los cultivos tradicionales, desarrollándose así la producción de hortalizas y verduras puesto que esto generan más ganancias económicas por la mayor comercialización; para 1979 se agregó a menor escala el cultivo de fresa, luego la mora y la manzana y en 1994 se 


\section{CIENCIAMATRIA \\ Revista Interdisciplinaria de Humanidades, Educación, Ciencia y Tecnología \\ Año V. Vol. V. No9. Julio - Diciembre 2019 \\ Hecho el depósito de ley: pp201602FA4721 \\ ISSN-L: 2542-3029; ISSN: 2610-802X \\ Universidad Nacional Experimental Francisco de Miranda (UNEFM). Santa Ana de Coro. Venezuela}

Jesús Alirio Briceño Briceño

desarrolla el cultivo del pompón. Por otra parte, los principales comercios privados del sector son: cuatro (4) bodegas, dos (2) distribuidores de hortalizas, un (1) latonería y pintura y dos (2) herrerías.

Así mismo, con el pasar del tiempo se ha venido poblando esta localidad, presentando el mayor crecimiento poblacional durante los años 1965-1990 y entre 2000-2008 aproximadamente, concentrándose la población a orillas de la carretera trasandina como resguardo de las tierras agrícolas, pues es la única fuente de ingresos económicos. Dentro de los logros en infraestructura pública se encuentran la construcción de la escuela Andrés Bello, La Capilla San Benito de Palermo, alumbrado eléctrico, un pequeño acueducto de agua para consumo, un sistema de riego "Tafallez" para satisfacer las necesidades principales de los pobladores y el desarrollo agrícola local, el Consejo Comunal de Chiquiao y el CBIT "Ramona Geralda de García" que funcionan en la escuela.

Así mismo, las viviendas en su mayoría son de una sola planta, con pequeños espacios de terrenos que generalmente son aprovechados como huertos o jardines familiares. El grupo familiar es nuclear, siendo éste una característica del lugar. Es de mencionar también, que en la comunidad se encuentran edificaciones antiguas de propiedad privadas, estas son protagonistas y guardan en sus tapias la historia de las primeras cuatro décadas del siglo XX.

Durante el año 1997 se construyó el Peaje de Chiquiao el cual no funcionó como recaudación de tarifa por el uso de la vía, sino que funciona eventualmente como casilla policial y refugio de los damnificados. De la misma manera, para el año 2005 se logró la construcción del módulo de Barrio Adentro atendido por médicos Cubanos.

Dentro de los dulces típicos se encuentra la realización de las denominadas arepas de horno, cuyos ingredientes son masa de maíz, panela y queso los cuales se amasan, se hacen las arepas y se hornean, así mismo, como tradición el día de San Juan Bautista y de San Pedro y San Pablo (24 y 29 de junio respectivamente) se realiza el Curruchete, 


\section{CIENCIAMATRIA \\ Revista Interdisciplinaria de Humanidades, Educación, Ciencia y Tecnología \\ Año V. Vol. V. №9. Julio - Diciembre 2019 \\ Hecho el depósito de ley: pp201602FA4721 \\ ISSN-L: 2542-3029; ISSN: 2610-802X \\ Universidad Nacional Experimental Francisco de Miranda (UNEFM). Santa Ana de Coro. Venezuela}

Jesús Alirio Briceño Briceño

preparado con panela en guarapo, queso cortado en trozos y pan picado. Por otra parte, en Semana Santa se realizan las carabinas, el cual es un preparado de masa de maíz aliñada envuelta en hoja de piñuela y cocida en agua.

\section{CONSIDERACIONES FINALES}

La comunidad de Chiquiao es una comunidad perteneciente al estado Trujillo, siendo este lugar el límite con el estado Mérida, esta condición le ha permitido ser protagonistas de diversos hechos históricos ocurrido en Venezuela, debido a que esta geográficamente ubicada, ya que permite la comunicación con los sectores cercanos a ella.

Dentro de las características geográficas se encuentra que está en el valle del rio Motatán, lo que la hace tener grandes potencialidades para el desarrollo agrícola y esta a su vez el crecimiento demográfico, esta virtud ofreció a los antepasados beneficios de estadía y de camino de paso. Para impulsar la agricultura se realizó con estrategia indígena la acequia comunal, que permitió distribuir el agua del rio Motatán y regar los terrenos.

Así mismo, dentro del aspecto histórico se encuentra distintas referencias bibliográficas que hacen observar la importancia del lugar, comenzando a que fue tomado por línea limítrofe por los grupos indígenas y en base a ello fue tomado como referencia para los conquistadores, por lo que indica que fue y es un lugar trascendental. De la misma manera, mediante la contrastación de los informantes se indica que en el lugar existió una casa donde se hospedó Bolívar en uno de los recorridos realizados por la zona andina.

Otro elemento a mencionar, es que por estar cerca de poblados como La Mesa de Esnujaque y Timotes, se ha beneficiado por el desarrollo y la comercialización en estos sectores, destacándose los caminos reales que pasaban por este lugar utilizado como vía de comercialización y el otro hecho importante como la construcción de la carretera 


\section{CIENCIAMATRIA \\ Revista Interdisciplinaria de Humanidades, Educación, Ciencia y Tecnología \\ Año V. Vol. V. №9. Julio - Diciembre 2019 \\ Hecho el depósito de ley: pp201602FA4721 \\ ISSN-L: 2542-3029; ISSN: 2610-802X \\ Universidad Nacional Experimental Francisco de Miranda (UNEFM). Santa Ana de Coro. Venezuela}

Jesús Alirio Briceño Briceño

trasandina en sus diferentes tramos y proyectos, esto incidió en la organización y crecimiento de la comunidad.

Actualmente se puede mencionar, que es una comunidad que ha crecido demográficamente y cuenta con los servicios básicos y estos a su vez son supervisados por los mismos habitantes. Dentro de la característica de las personas es el trato agradable, pues la mayoría de los habitantes se ha conservado el respeto, la honestidad y la responsabilidad.

Finalmente se puede decir, que para desarrollar y mejorar la nación se necesita resaltar estos valores históricos, culturales y geográficos, ya que por medio de esto nos ayuda a arraigar y dar la pertinencia de nuestra identidad; se tiene que comenzar con pequeños pasos, en una comunidad pequeña, para luego ir adentrándose a otros terrenos para vislumbrar y diversificar el conocimiento que se encuentra escondido en las personas que han vivido los hechos y deben ser rescatados; todo esto le da relevancia a lo descrito por Morón (2014: 82) citando a De Lima "no se puede investigar la historia de otros países sin antes haber ahondado en la propia; si es así, hay destellos que indican que algo no anda bien, que el proceso de enseñanza aprendizaje no anda bien".

\section{REFERENCIAS CONSULTADAS}

1. Aponte E. (2006). La geohistoria, un enfoque para el estudio del espacio Venezolano desde una perspectiva interdisciplinaria. Documento en línea, disponible en: http://www.ub.edu/geocrit/sn/sn-218-08.htm. Consultado el $\underline{14 / 03 / 2014}$.

2. Asamblea Nacional Constituyente. (1999) Constitución de la República Bolivariana de Venezuela. Distribuidora Escolar. Caracas-Venezuela.

3. Avella, F. (2002). El Caribe: bases para una geohistoria. Documento en línea, disponible en: http://www.catedras-bogota.unal.edu.co/ancizar/2011- 
II/6_catedra\%20manuel\%20ancizar/catedra\%20manuel\%20ancizar/docs/S6\%20$\% 20$ Avella-_El_Caribe_Bases_para_una_Geohistoria.pdf Consultado el 13/09/2013.

4. Ceballos B. (2003) La Geohistoria como una respuesta a la necesidad social Contemporánea. Documento en línea, disponible en: http://files.geohistoriaentussmanos.webnode.es/200000017b0548b14e7/La\%20Geohistoria\%20como\%20respuesta\%20a\%20la\%20necesid ad\%20social\%20contempor\%C3\%A1nea.pdf . Consultado el 13/09/2013.

5. Gordones g y otros. (2004). El poblamiento prehispánico de la cordillera Andina de Mérida-Venezuela. Boletín Antropológico. Año 22, $\mathrm{N}^{\circ} 60$. Universidad de los Andes. https://www.saber.ula.ve/bitstream/123456789/18506/1/articulo2.pdf. Consultado el 19/01/2012.

6. Jahn A. (1927). Los Aborígenes del Occidente de Venezuela Su Historia, Etnografía y Afinidades Lingüísticas. Caracas-Venezuela.

7. Morón G. (2014). Blanca Isabel De Lima, conoce nuestra médula histórica. Revista edición especial "Hechos de la ciencia" del diario Nuevo Día. Edición aniversaria 2014.

8. Muñoz C. (1971). Los Comuneros de Venezuela. Universidad de los Andes. Facultad de Humanidades y Educación. Mérida-Venezuela.

9. Pimiento G. y otros (2008). La primera fundación de Mérida como problema histórico e historiográfico. Anuario GRHIAL. Universidad de los Andes. MéridaVenezuela. Disponible

en: http://www.saber.ula.ve/bitstream/123456789/27849/1/articulo8.pdf. Consultado el 19/01/2012.

10. Quevedo Pérez, D., Noriero Escalante, L., Cervantes Herrera, J., \& Zepeda del Valle, J. (2016). Las representaciones sociales de los Teenek de Tamaletom, en el municipio de Tancanhuitz, San Luis Potosí, México. Revista Arbitrada Interdisciplinaria Koinonía, 1(2), 30-49. Recuperado de http://fundacionkoinonia.com.ve/ojs/index.php/revistakoinonia/article/view/38/26

11. Santaella R. (2005). Pensamiento Geohistórico de Ramón Adolfo Tovar López. Red de revistas científicas de América Latina, El Caribe, España y Portugal. 
Jesús Alirio Briceño Briceño

Redalyc.org. Documento en línea, disponible en: http://www.redalyc.org/pdf/360/36010101.pdf. Consultado el 25/03/2015.

12. Villareal, E (2008). Ecos de Mucurujún. Crónica Histórica. Colección de autores Timotenses. $N^{\circ} 6$. Timotes estado Mérida.

13. Hemeroteca: Periódico "El Trujillano" del 13 de Agosto de 1881.

14. Informantes clave: Abreu C. (2012). Briceño E, Briceño J, Díaz A, Espinoza J, García J, García M, Gómez G, Salcedo H, Villarreal I, Villareal E. (2011)

15. Informantes clave no nombrado en la investigación: Araujo A, Briceño G. (2011).

(C2019 por el autor. Este artículo es de acceso abierto y distribuido según los términos y condiciones de la licencia Creative Commons Atribución-NoComercial-Compartirlgual 4.0 Internacional (CC BY-NC-SA

4.0) (https://creativecommons.org/licenses/by-nc-sa/4.0/). 